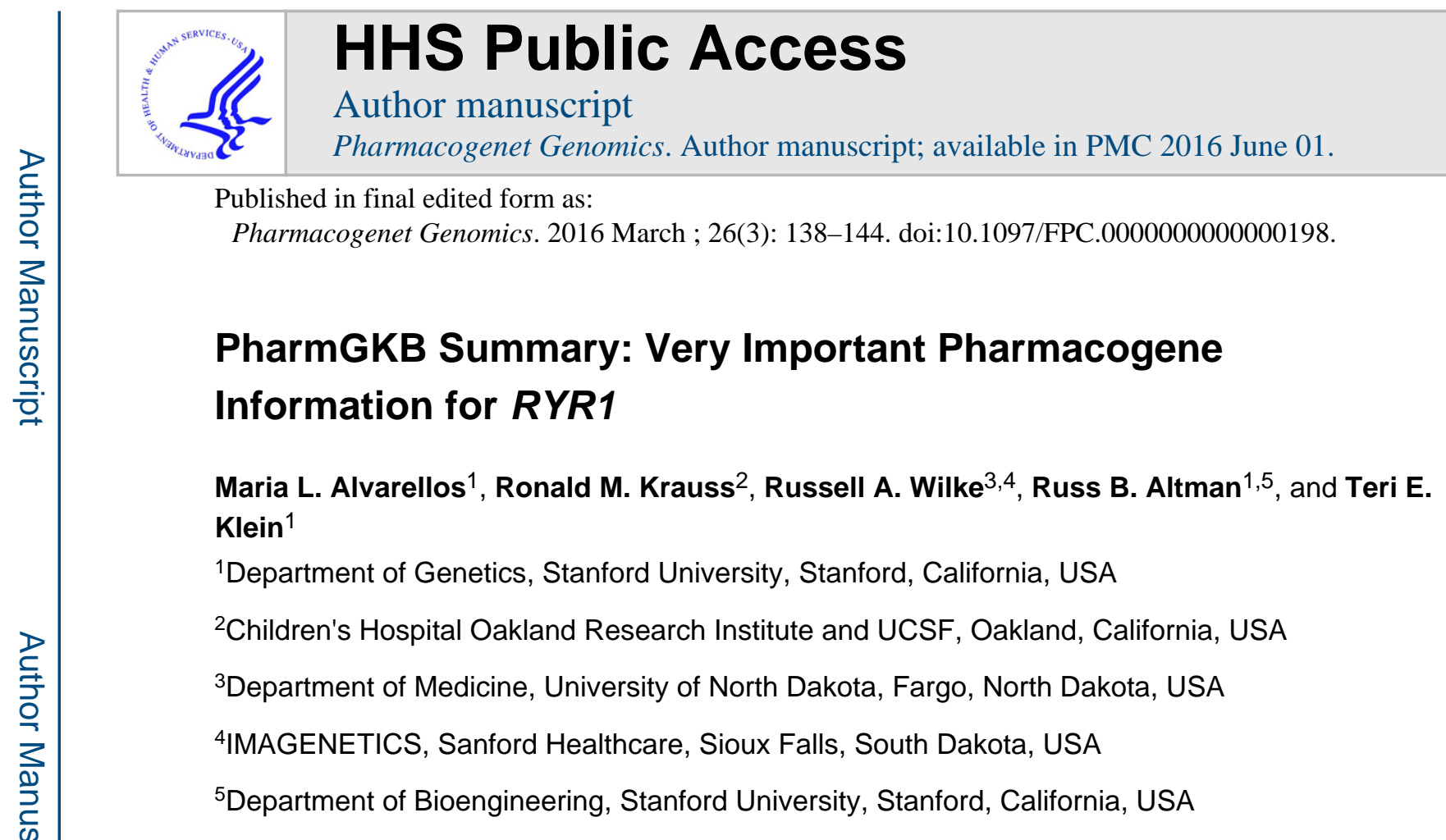

\title{
Keywords
}

calcium homeostasis; malignant hyperthermia; myopathy; rhabdomyolysis; ryanodine receptor; RYR1; statin; succinylcholine; volatile anesthetics

\begin{abstract}
The RYRl gene encodes the ryanodine receptor isoform 1 (RYR1), a homotetrameric calcium channel found on the terminal cisternae of the sarcoplasmic reticulum (SR) of skeletal muscle, cardiac muscle, smooth muscle cells, and the endoplasmic reticulums of Blymphocytes and cerebellar Purkinjie cells. RYR1 plays a critical role in calcium release and muscle contraction in skeletal muscle. Many RYRl variants are implicated in neuromuscular diseases of varying severity and dozens of genetic variants in RYRl influence patient risk for developing drug-induced myopathies such as malignant hyperthermia (MH) [1, 2]. MH is a potentially lethal condition triggered by potent inhalational anesthetics and depolarizing muscle relaxants. The incidence of $\mathrm{MH}$ is rare; estimates of the incidence of $\mathrm{MH}$ range from 1 of 10,000 to 1 of 250,000 anesthesias. However, the genetic prevalence of MH susceptibility (MHS) has been estimated to be as high as 1 out of 400 individuals [2]. The American College of Medical Genetics (ACMG) 2013 report on recommendations for clinical exome and whole genome sequencing analyses includes $R Y R l$ in its list of genes to report in incidental findings [3]. This review will focus on RYRI in skeletal muscle because it is the primary locus for MHS and will also explore the potential impact of genetic variation in RYRl on other drug-induced myopathies accompanying the use of HMG Co-A reductase inhibitors (statins). An interactive version of this review can be accessed at (https://www.pharmgkb.org/gene/PA34896).
\end{abstract}

Corresponding Author: Dr. Teri E. Klein, Shriram Center for Bioengineering and Chemical Engineering, 443 Via Ortega, Room 213, MC: 4245 Stanford, CA 94305, Phone: (650)-725-0659, FAX: (650)-725-3863, feedback@ pharmgkb.org.

Conflict of Interest

R.B.A and T.E.K are stockholders for Personalis Inc. For the remaining authors, there are no conflicts of interest. 


\section{The role of RYR1 in skeletal muscle}

\section{Excitation-contraction coupling and skeletal muscle contraction}

Depolarization of the sarcolemma activates dihydropyridine receptors (DHPRs), which are voltage-gated ion channels that are mechanically coupled to RYR1. The activation of DHPRs, in turn opens RYR1, which releases calcium stores from the sarcoplasmic reticulum (SR) $[4,5]$. Calcium ions stimulate muscle contraction by binding troponin $\mathrm{c}$, which displaces tropomyosin from the actin active site, and allows myosin to bind to actin to generate a contraction [6]. Muscle contraction ends when the sarcolemma repolarizes, RYR1 channels close, and calcium ATPases known as SERCAs pump calcium ions back into the SR $[5,7]$. Although the SR is the primary source of myoplasmic calcium in skeletal muscle, extracellular calcium entry may also occur when SR stores become depleted (store operated calcium entry) [8] or during moments of sustained depolarization (excitation coupled calcium entry) $[9,10]$.

\section{RYR1 protein structure and regulation}

The three mammalian ryanodine receptor protein isoforms (RYR1, RYR2, and RYR3) share $\sim 65 \%$ sequence similarity, and all are expressed in skeletal muscle, although RYR1 predominates [7]. RYR1 is also found in cardiac muscle, cerebellar Purkinjie cells, Blymphocytes, and various other cell types. RYR2 is the predominant isoform in cardiac muscle fibers, but it is also found in skeletal muscle, Purkinjie cells of the cerebellum and cerebral cortex, and to a lesser extent in visceral and arterial smooth muscle, and other cell types. RYR3 is the predominant isoform in brain cells such as hippocampal neurons, thalamus, Purkinjie cells, and the corpus striatum $[4,7,11]$.

RYRI encodes one sub-unit of the homotetrameric RYR1 channel and each RYR1 protein is 5038 amino acids long and weighs $\sim 565 \mathrm{kDa}$ [12]. The proteins assemble into a quatrefoil structure organized around an ion-conducting pore. Approximately $80 \%$ of the volume of the channel is myoplasmic-facing and the other $20 \%$ is composed of the transmembrane domain and ion pore $[4,7]$. RYR1 exists as part of a protein complex that includes the 12 kDa immunophilin FK506 binding protein (FKBP12) and calmodulin (CaM), which regulate RYR1 on its myoplasmic facing side. FKBP12 binds and stabilizes the closed conformation of RYR1. Calcium free CaM is a weak partial agonist of RYR1 that promotes the open conformation of the channel, and calcium bound CaM is a stronger antagonist of RYR1 that promotes the closed conformation of the channel $[11,12]$. Proteins within the SR lumen also regulate calcium storage and release from RYR1. The most abundant SR luminal protein in skeletal muscle, calsequestrin (CSQ1), is a low-affinity and high capacity calcium buffer that allows the SR to store high concentrations of calcium. CSQ1 has no transmembrane domains but it remains close to the junctional face of RYR1 by anchoring to the integral membrane proteins junctin and triadin $[12,13]$. Triadin binds to an intraluminal loop of RYR1 and is hypothesized to facilitate rapid release of calcium by maintaining CSQ1-bound calcium close to the RYR1 channel pore $[12,14]$ while junctin has been shown to be necessary for normal RYR1 function and may communicate signals between CSQ1 and RYR1 [15]. 
The myoplasmic facing side of RYR1 contains few high-affinity activating sites and many low-affinity inactivating sites to which calcium can bind [11, 16]. At steady state conditions lower myoplasmic calcium concentrations $(\sim 100 \mathrm{nM}$ to $10 \mu \mathrm{M})$ activate RYR1 by increasing its open probability while higher concentrations of calcium (between $\sim 100 \mu \mathrm{M}$ and $\sim 10 \mathrm{mM}$ ) inactivate RYR1 by decreasing its open probability [4]. Magnesium ions inhibit RYR1 activation by competing with calcium for the activating sites on RYR1, as well as by binding the inhibitory sites $[4,11]$. Half of the RYR1 proteins are not physically close enough to be allosterically regulated by the DHPR and instead they open in response to local elevations in calcium [16].

\section{Pharmacological agents that interact with RYR1}

RYRs get their name from ryanodine, a plant alkaloid that preferentially binds open ryanodine receptors [17, 18]. Caffeine activates RYR1 by reducing the inhibitory effects of magnesium while enhancing the activating effects of calcium [19] and it has also been shown to potentiate calcium induced calcium release [16]. Dantrolene, a muscle relaxant, is the only known pharmacological treatment for MH. Its introduction into routine clinical use in the 1970s drastically reduced the mortality rate of $\mathrm{MH}$ from $\sim 80 \%$ to $\sim 5 \%$ now $[2,20]$. Studies have shown evidence that dantrolene has multiple mechanisms of action: it binds to and stabilizes RYR1 in its closed state [21], it inhibits excitation coupled calcium entry [10] without affecting the propagation of action potentials [20], and it restricts communication between the DHPR and RYR1 during retrograde signaling between the two channels [22].

\section{Molecular genetics}

The RYR1 gene, located on chromosome 19q13.2, contains 106 exons and it encodes a cDNA that is $\sim 160 \mathrm{~kb}$ in length [23]. $R Y R l$ is critically important for proper morphological development; RYRl knockout mice exhibit excitation contraction uncoupling as well as gross musculoskeletal deformities and die perinatally, possibly due to respiratory failure [12, $24,25]$. There are also two known splice variants of $R Y R l$ whose expression is regulated in a temporal and tissue-specific manner, particularly during development [26, 27]. RYRI expression may also be regulated by muscle use in adults. A study in twenty healthy adult male volunteers over a period of 56 days reported that increased muscle use positively affected $R Y R I$ gene expression while disuse negatively affected $R Y R I$ gene expression [28].

\section{RYR1 Pharmacogenetics}

\section{Malignant hyperthermia}

$\mathrm{MH}$ is a rare pharmacogenetic condition that is triggered by depolarizing muscle relaxants and potent inhalational anesthetics, also known as volatile anesthetics. At the cellular level, $\mathrm{MH}$ is a hypermetabolic state caused by an uncontrollable rise in myoplasmic calcium. Early symptoms of MH are hypercapnia, metabolic and respiratory acidosis, and muscle contractures. Without sufficient intervention, subsequent and more serious symptoms include rhabdomyolysis (breakdown of skeletal muscle tissue), hyperthermia, tachycardia, and cardiac arrest [2]. MH symptoms can arise in a rapid and dramatic fashion in otherwise healthy patients (fulminant $\mathrm{MH}$ ), or they may appear gradually long after trigger agents are 
discontinued (attenuated MH) [29]. During an MH episode, high myoplasmic calcium concentrations cause strong and persistent muscle contractions, which can result in rhabdomyolysis while the ATP intensive removal of myoplasmic calcium by SERCAs in myocytes may cause hyperthermia [4]. In addition, B-lymphocytes, which also express $R Y R I$, may contribute to hyperthermia because they release a pyrogenic cytokine called IL-6 in the presence of anesthetic triggers [30-32].

\section{Variability in MH Phenotypes}

MH varies in presentation and severity. A retrospective study (1972-2010) of 200 patients tested for MHS in seven MH Units across Europe reported that the severity of an MH crisis, as determined by clinical grading scale (CGS) score, was affected by several genetic and non-genetic factors. The CGS score estimates the probability that an MH event has taken place (e.g. "not likely" to "almost certain") and is based on the number and type of symptoms an individual has experienced. Enflurane produced the highest CGS score when compared to halothane, isoflurane, and desflurane although most crises were triggered by halothane [33].

\section{Triggers of Malignant Hyperthermia}

According to the European Malignant Hyperthermia Group (EMHG), an MH research consortium, and the Malignant Hyperthermia Association of the United States (MHAUS) all inhaled anesthetics except nitrous oxide (e.g. ether, halothane, enflurane, sevoflurane, isoflurane, desflurane, and methoxyflurane), either alone or in conjunction with a depolarizing neuromuscular relaxant (e.g. succinylcholine), are considered triggers of $\mathrm{MH}$, and should be avoided in MHS individuals [2, 34, 35]. Volatile anesthetics act on a multitude of known and as yet undiscovered molecular targets, which is surprising considering how routinely they are used [36]. What is known is that volatile anesthetics induce hypnosis and sedation by acting on multiple molecular targets in the brain, and they induce immobilization by acting on multiple targets in the spinal cord. Some of the targets of volatile anesthetics include voltage-gated ion channels, excitatory receptors (e.g. neuronal nicotinic acetylcholine receptors), as well as inhibitory receptors (e.g. $\gamma$-aminobutyricacid (GABA) receptors and glycine receptors) [36-38]. Volatile anesthetics stimulate SRmediated calcium release [33], and evidence suggests that they act through RYR1, although the precise mechanism by which this occurs is unknown [39-41]. Succinylcholine (SCH) is a depolarizing neuromuscular block that causes short-term muscle paralysis. Upon first binding to the nicotinic acetylcholine receptor $\mathrm{SCH}$ induces membrane depolarization, calcium release via RYR1, and muscle fasiculations, and by inhibiting membrane repolarization, it causes flaccid muscle paralysis $[42,43]$. The individual capacity of SCH to trigger MH is still unclear because it is almost always administered with a volatile anesthetic. In addition, 4-chloro-m-cresol used to be added to $\mathrm{SCH}$ preparations as a preservative agent until it was discovered to be a RYR1 activator $[44,45]$ and it was subsequently removed [33]. The evidence suggests that $\mathrm{SCH}$ alone rarely triggers $\mathrm{MH}$ but when it is co-administered with a volatile anesthetic the onset of MH symptoms may be more rapid $[33,46]$. 


\section{Genetics of MHS}

MHS is inherited in an autosomal dominant manner, and closely related members of a family in which MH has occurred should also be considered at risk for MHS and should be managed accordingly (see below) [47]. All known MHS-causative mutations greatly increase an individual's likelihood of experiencing an $\mathrm{MH}$ reaction when administered $\mathrm{SCH}$ or volatile anesthetics, but specific RYRI mutations also correlate with MHS phenotype. For example, some mutations are associated with MHS as well as central core disease (CCD) while some are associated with MHS without CCD (MHS-only) [33, 48]. RYRI mutations that result in an MHS-only phenotype tend to cluster in the N-terminal domain of $R Y R I$ and RYRI mutations that result in an MHS/CCD phenotype tend to cluster within three hot spots: amino acid residues 35- 614 (MHS/CCD 1), 2163-2458 (MHS/CCD 2), and 4664-5020 (MHS/CCD 3) [33].

The severity of a patient's MHS reaction may also be correlated with the type of $R Y R I$ mutation that the patient carries. In a study comparing the in vitro contracture tests (IVCT) (see below) of 297 unrelated individuals in the United Kingdom, the MHS/CCD associated mutations were associated with stronger muscle contractions at lower concentrations of caffeine and halothane as compared to MHS-only associated mutations [49]. A second study reported that carriers of mutations in an MHS/CCD "hot-spot" had a more severe MH crisis as compared to patients with RYRI mutations outside of the hot-spots [33]. Finally, a third study reported that specific mutations, particularly in evolutionarily conserved amino acid residues, also correlated with severity of an MH reaction and strength of IVCT contracture, supporting the notion that phenotypic variability in $\mathrm{MH}$ reactions is influenced by genetic as well as non-genetic factors, such as the type of anesthetic that was used [50].

Current evidence suggests that $R Y R I$ mutations that cause MHS are associated with basal elevations in myoplasmic calcium and increased sensitivity of RYR1 to trigger anesthetics. A generally accepted working hypothesis is that all MHS-causative mutations in RYRI disrupt bonds between key amino acids that maintain the stability of the closed confirmation of the channel. This is hypothesized to cause RYR1 to "leak" calcium leading to higher myoplasmic calcium concentrations and RYR1 hypersensitivity to agonist stimulation [48, 51-55]. In addition, it is hypothesized that MHS/CCD mutations cause RYR1 to be more "leaky" than MHS-only mutations. This increased calcium leak is proposed to cause depletion of SR calcium stores in MHS/CCD associated mutations while the less leaky MHS-only mutations are proposed to cause more modest elevations in myoplasmic calcium without SR calcium store depletion. The symptom of muscle weakness associated with MHS/CCD mutations may be partly attributed to SR calcium store depletion and the formation of "central cores" may be due to increased oxidative stress as a result of elevated calcium levels $[48,56]$.

\section{Other drug-induced myopathies}

There is wide phenotypic variability in the clinical manifestation of muscle toxicity for several orally administered medications such as HMG-CoA reductase inhibitors (statins) [57, 58]. Efforts are being made to standardize the clinical definition of these traits [59], and automated decision support is being deployed in the context of routine clinical practice to 
identify patients at risk [60]. For example, a study of statin-exposed patients identified 2,227 individuals with creatine kinase (CK) levels in the upper 10th percentile from among $~ 2$ million unique patients by scanning electronic medical records [57]. Further exploratory analyses using a pathway-based approach have suggested that variants in multiple members of the $R Y R$ gene family may alter patient risk for statin-associated myopathy [61, 62]. In support of those findings, $R Y R l$ variants, including MHS-causative mutations, have been discovered in patients with severe and mild statin-associated myopathy, including rhabdomyolysis and abnormally high plasma CK [1]. In addition, genome-wide SNP scanning study conducted in 185 patients who experienced rhabdomyolysis while taking cerivastatin revealed a strong association between severe statin-induced muscle damage and variant markers at the $R Y R 2$ locus [63].

\section{RYR1 associated myopathies in the absence of drug exposure}

Some patients that develop recurrent rhabdomyolysis, or abnormal elevations of CK after intense exercise or in high heat have subsequently been diagnosed as MHS via IVCT or CHCT [64-67]. Central Core Disease (CCD) is characterized by proximal muscle weakness and while individuals experience motor development delays from early childhood others may go undiagnosed until they are adults $[11,68]$. The most severe clinical symptoms are hypotonia and weakness of the extremities, hip dysplasia, and scoliosis. CCD can be diagnosed histologically because muscle fibers contain characteristic lesions called "cores", which are disorganized muscle fiber bundles with few mitochondria and decreased oxidative phosphorylation activity. Cores extend lengthwise across type I fibers and the reason that they occur is unknown [68]. Some RYRI mutations cause both CCD and MHS, while some only cause CCD $[69,70]$. Multiminicore disease $(\mathrm{MmD})$ is associated with a more profound muscle weakness as compared to $\mathrm{CCD}$ [71]. Although $\mathrm{MmD}$ is often attributed to mutations in RYRl, mutations in other genes have also been implicated. The condition is more difficult to classify histologically than CCD: cores tend to be short and dispersed throughout the muscle fiber [12, 71, 72]. MmD is occasionally co-diagnosed with MHS, so individuals who are diagnosed with MmD should be considered as candidates for MHS and non-triggering anesthetic agents should be used when necessary. RYRI mutations that are associated with MmD may affect gene expression, protein stability, or sensitivity of the RYR1 channel to agonist stimulation [71].

\section{Testing for Malignant Hyperthermia Susceptibility}

Without a diagnosis of CCD or MmD, individuals who are MH susceptible (MHS) tend to be asymptomatic, although some individuals experience multiple episodes of heat and exercise induced rhabdomyolysis before they are diagnosed as MHS [64-66]. According to the MHAUS, diagnostic testing for MHS is not recommended as a screening tool, and should only be undertaken after the detailed medical and family history of a patient suggests that he or she may be MHS, particularly if that patient is awaiting surgery. Typically, patients with a previous episode of suspected, or confirmed MH in the presence of trigger agents, or with a family history of MHS are good candidates for diagnostic testing [73, 74]. The two diagnostic test options for MHS are the in vitro contracture test (IVCT, or caffeine halothane contracture test in the U.S) or a genetic test of RYRI and CACNAIS. 


\section{In vitro contracture test and caffeine-halothane contracture test}

The current gold standard for MHS diagnosis is the in vitro contracture test (IVCT). A very similar procedure, with slight protocol differences is called the caffeine halothane contracture test (CHCT) in the United States. The IVCT is 97-99\% sensitive and $93.6 \%$ specific in detecting MHS [45]. The test requires a skeletal muscle biopsy to be done with a non-triggering anesthetic or a femoral nerve block. The IVCT consists of exposing freshly dissected vastus lateralis or vastus medialis muscle fibers to increasing concentrations of caffeine and halothane separately, and assaying the muscle fibers' sensitivity to each by measuring the force of contracture with a myo-electrical transducer. If the force of contracture is $<2$ millinewton $(\mathrm{mN})$ at a $2 \%$ volume of halothane or 2 millimolar $(\mathrm{mM})$ of caffeine, the diagnosis is $\mathrm{MH}$ negative (MHN). If the force of contracture is $\geq$ to $2 \mathrm{mN}$ when tested with halothane and caffeine the diagnosis is MHShc, but if the force of contracture is $\geq 2 \mathrm{mN}$ with either halothane, or caffeine, but not both, the diagnosis is MHSh, or MHSc, respectively. The term $\mathrm{MH}$ equivocal for patients that were sensitive to either caffeine or halothane was recently changed to MHSh or MHSc for halothane, or caffeine [73]. A major limitation of the IVCT/CHCT is that specialized testing centers are scarce. According to the Malignant Hyperthermia Association of the United States (MHAUS), there are only five testing centers in North America: 1 in Canada and 4 in the United States MHAUS [75].

\section{Genetic Testing of RYR1}

The EMHG maintains a list MHS diagnostic mutations: as of the writing of this manuscript, 35 variants in $R Y R 1$, and 2 variants in CACNAIS are designated MHS-causative [74, 76]. CACNAIS encodes the a1s sub-unit of the skeletal muscle DHPR, which contains the voltage sensor for the receptor. It is important to note that the CACNAIS mutations on the EMHG list are very rare, even among MHS patients [76-79]. Ever since RYRI was discovered to be the primary locus for MHS it was hoped that a genetic test could be developed to replace the IVCT. However, it quickly became clear that genetic testing also had limitations [80]. First, 30-50\% of MHS families have no known MHS-causative mutations in RYRI, which could be attributed to selective sequencing (e.g. hot-spot sequencing instead of whole gene). Second, there are reported incidences of discordance between RYRI genotype and IVCT result, which further limits the diagnostic potential of genetic testing to diagnose individuals as MHN. RYRI is highly polymorphic and the list of variants, including variants of unknown significance, continues to increase [81]. The Database of Single Nucleotide Polymorphisms (dbSNP) currently lists hundreds of single nucleotide polymorphisms (SNPs) in RYR1 [82].

The EMHG released genetic testing guidelines in 2001 that recommended muscle biopsy and IVCT as the primary method of diagnosis in individuals referred to MH investigative centers for diagnostic testing. Mutation screening was only recommended for individuals who were diagnosed as MHS via IVCT, and their relatives. The EMHG also recommended that first-degree relatives of an MHS proband with an MHS-positive variant undergo IVCT to confirm their MHN status [83, 84]. The MHAUS still recommends that patients who are suspected of being MHS be tested first by CHCT and that genetic testing should be used only after a positive diagnosis, or if an MHS-causative variant is known to run in a family it 
can be used to test relatives for MHS. In the case of very small children who are too young to undergo CHCT, the MHAUS does recommend genetic testing first [74].

In 2015, the EMHG revised its guidelines and now considers genetic testing of $R Y R I$ and CACNAIS to be a viable primary diagnostic approach, provided that a diagnostic mutation is detected. For example, if a diagnostic mutation is found in an MHS proband the mutation can be used for predictive testing of relatives. The EMHG guideline recommends that the decision to pursue genetic testing or IVCT first be considered on a case-by-case basis and should include input from the MH diagnostic center, the physician, and patient. Test availability and turnaround time, as well whether a patient is awaiting surgery should be considered when making the decision [73]. The revised EMHG guidelines also consider "potentially MHS-associated" variants as increasing an individual's risk of MHS until IVCT can be performed. The EMHG has also revised its criteria for mutations to be considered MHS-causative: novel variants may now be considered for inclusion on the EMHG's list of diagnostic variants if functional studies of the variant were conducted using "rigorous genetic manipulation of heterologous or homologous expression systems". Functional studies may now be peer reviewed by EMHG experts before being added to their list [73]. The ACMG has also released recommendations for the reporting of incidental findings in clinical exome and genome sequencing. The published recommendations have a list of conditions, genes and variants that should be returned as incidental findings, and RYRl, $C A C N A 1 S$, and malignant hyperthermia susceptibility are included. In the event that a pathogenic variant in a gene on the list is discovered, the ACMG recommends that clinical sequencing laboratories consult medical databases and the scientific literature to support the diagnosis of variant pathogenicity before reporting it as an incidental finding [3].

\section{Conclusions and future directions}

A unified understanding of the mechanisms underlying the pathogenesis of heritable and drug-induced myopathies is emerging due to the myriad functional analyses that have been undertaken to describe the RYR1 channel and its associated proteins. Gene expression studies and genome wide SNP scanning have implicated $R Y R l$ variants in a variety of druginduced myopathies, including severe muscle damage, in the context of inhalational anesthetics. Efforts to investigate the specific mutations in RYRI that cause MHS were initially hampered by the technical difficulties of sequencing this large gene but advances in sequencing technology have increased the accuracy and efficiency of RYRI sequencing and allowed for the detection of novel variants in individuals who are diagnosed as MHS.

Although genetic testing is of limited value for MHS individuals in whom no plausibly causative mutations are found the possibility of testing for MHS using B-lymphocytes in lieu of the IVCT appears promising but requires further validation [30, 31, 85-87]. Given the advances in genetic testing, anesthesiologists and patients would benefit from the inclusion of more comprehensive information on the genetics of $\mathrm{MH}$ on trigger anesthetic drug labels. Thankfully, MH is rare and easily preventable if MHS patients are identified and non-trigger anesthetics are utilized. 


\section{Acknowledgments}

The authors thank Li Gong, Julia Barbarino, and Michelle Whirl-Carrillo for their excellent comments and close reading of the manuscript. PharmGKB is supported by the NIH/NIGMS R24 GM61374. Dr. Krauss is supported by the "Pharmacogenomics of Statin Therapy" NIH/NIGMS 1P50GM115318-01.

\section{References}

1. Vladutiu GD, Isackson PJ, et al. Genetic risk for malignant hyperthermia in non-anesthesia-induced myopathies. Mol Genet Metab. 2011; 104:167-173. [PubMed: 21795085]

2. Rosenberg H, Pollock N, et al. Malignant hyperthermia: a review. Orphanet J Rare Dis. 2015; 10:93. [PubMed: 26238698]

3. Green RC, Berg JS, et al. ACMG recommendations for reporting of incidental findings in clinical exome and genome sequencing. Genet Med. 2013; 15:565-574. [PubMed: 23788249]

4. Capes EM, Loaiza R, et al. Ryanodine receptors. Skelet Muscle. 2011; 1:18. [PubMed: 21798098]

5. Rebbeck RT, Karunasekara Y, et al. Skeletal muscle excitation-contraction coupling: who are the dancing partners? Int J Biochem Cell Biol. 2014; 48:28-38. [PubMed: 24374102]

6. Frontera WR, Ochala J. Skeletal muscle: a brief review of structure and function. Calcif Tissue Int. 2015; 96:183-195. [PubMed: 25294644]

7. Amador FJ, Stathopulos PB, et al. Ryanodine receptor calcium release channels: lessons from structure-function studies. FEBS J. 2013; 280:5456-5470. [PubMed: 23413940]

8. Pan Z, Brotto M, et al. Store-operated Ca2+ entry in muscle physiology and diseases. BMB Rep. 2014; 47:69-79. [PubMed: 24411466]

9. Yang T, Allen PD, et al. Enhanced excitation-coupled calcium entry in myotubes is associated with expression of RyR1 malignant hyperthermia mutations. J Biol Chem. 2007; 282:37471-37478. [PubMed: 17942409]

10. Cherednichenko G, Ward CW, et al. Enhanced excitation-coupled calcium entry in myotubes expressing malignant hyperthermia mutation R163C is attenuated by dantrolene. Mol Pharmacol. 2008; 73:1203-1212. [PubMed: 18171728]

11. Lanner JT, Georgiou DK, et al. Ryanodine receptors: structure, expression, molecular details, and function in calcium release. Cold Spring Harb Perspect Biol. 2010; 2:a003996. [PubMed: 20961976]

12. Hwang JH, Zorzato F, et al. Mapping domains and mutations on the skeletal muscle ryanodine receptor channel. Trends Mol Med. 2012; 18:644-657. [PubMed: 23069638]

13. Beard NA, Laver DR, et al. Calsequestrin and the calcium release channel of skeletal and cardiac muscle. Prog Biophys Mol Biol. 2004; 85:33-69. [PubMed: 15050380]

14. Goonasekera SA, Beard NA, et al. Triadin binding to the C-terminal luminal loop of the ryanodine receptor is important for skeletal muscle excitation contraction coupling. J Gen Physiol. 2007; 130:365-378. [PubMed: 17846166]

15. Li L, Mirza S, et al. A new cytoplasmic interaction between junctin and ryanodine receptor $\mathrm{Ca} 2+$ release channels. J Cell Sci. 2015; 128:951-963. [PubMed: 25609705]

16. Endo M. Calcium-induced calcium release in skeletal muscle. Physiol Rev. 2009; 89:1153-1176. [PubMed: 19789379]

17. Chu A, Diaz-Munoz M, et al. Ryanodine as a probe for the functional state of the skeletal muscle sarcoplasmic reticulum calcium release channel. Mol Pharmacol. 1990; 37:735-741. [PubMed: 1692609]

18. McGrew SG, Wolleben C, et al. Positive cooperativity of ryanodine binding to the calcium release channel of sarcoplasmic reticulum from heart and skeletal muscle. Biochemistry. 1989; 28:16861691. [PubMed: 2541762]

19. Herrmann-Frank A, Luttgau HC, et al. Caffeine and excitation-contraction coupling in skeletal muscle: a stimulating story. J Muscle Res Cell Motil. 1999; 20:223-237. [PubMed: 10412093]

20. Krause T, Gerbershagen MU, et al. Dantrolene--a review of its pharmacology, therapeutic use and new developments. Anaesthesia. 2004; 59:364-373. [PubMed: 15023108] 
21. Kobayashi S, Bannister ML, et al. Dantrolene stabilizes domain interactions within the ryanodine receptor. J Biol Chem. 2005; 280:6580-6587. [PubMed: 15611117]

22. Bannister RA. Dantrolene-induced inhibition of skeletal L-type Ca2+ current requires RyR1 expression. Biomed Res Int. 2013; 2013:390493. [PubMed: 23509717]

23. Online Mendelian Inheritance in Man, OMIM®. Baltimore, MD: Johns Hopkins University; MIM Number: 177400: 09/17/2013. http://www.omim.org/entry/180901 [Accessed [August 11, 2015]]

24. Takeshima $\mathrm{H}$, Iino $\mathrm{M}$, et al. Excitation-contraction uncoupling and muscular degeneration in mice lacking functional skeletal muscle ryanodine-receptor gene. Nature. 1994; 369:556-559. [PubMed: 7515481]

25. Barone V, Bertocchini F, et al. Contractile impairment and structural alterations of skeletal muscles from knockout mice lacking type 1 and type 3 ryanodine receptors. FEBS Lett. 1998; 422:160164. [PubMed: 9489997]

26. Futatsugi A, Kuwajima G, et al. Tissue-specific and developmentally regulated alternative splicing in mouse skeletal muscle ryanodine receptor mRNA. Biochem J. 1995; 305(Pt 2):373-378. [PubMed: 7832748]

27. Kimura T, Pace SM, et al. A variably spliced region in the type 1 ryanodine receptor may participate in an inter-domain interaction. Biochem J. 2007; 401:317-324. [PubMed: 16989644]

28. Salanova M, Schiffl G, et al. Ryanodine receptor type-1 (RyR1) expression and protein Snitrosylation pattern in human soleus myofibres following bed rest and exercise countermeasure. Histochem Cell Biol. 2008; 130:105-118. [PubMed: 18283481]

29. Broman M, Islander G, et al. Malignant hyperthermia, a Scandinavian update. Acta Anaesthesiol Scand. 2015; 59:951-961. [PubMed: 25989378]

30. Sei Y, Brandom BW, et al. Patients with malignant hyperthermia demonstrate an altered calcium control mechanism in B lymphocytes. Anesthesiology. 2002; 97:1052-1058. [PubMed: 12411786]

31. Girard T, Cavagna D, et al. B-lymphocytes from malignant hyperthermia-susceptible patients have an increased sensitivity to skeletal muscle ryanodine receptor activators. J Biol Chem. 2001; 276:48077-48082. [PubMed: 11673462]

32. Ducreux S, Zorzato F, et al. Effect of ryanodine receptor mutations on interleukin-6 release and intracellular calcium homeostasis in human myotubes from malignant hyperthermia-susceptible individuals and patients affected by central core disease. J Biol Chem. 2004; 279:43838-43846. [PubMed: 15299003]

33. Klingler W, Heiderich S, et al. Functional and genetic characterization of clinical malignant hyperthermia crises: a multi-centre study. Orphanet J Rare Dis. 2014; 9:8. [PubMed: 24433488]

34. Glahn KP, Ellis FR, et al. Recognizing and managing a malignant hyperthermia crisis: guidelines from the European Malignant Hyperthermia Group. Br J Anaesth. 2010; 105:417-420. [PubMed: 20837722]

35. Safe and Unsafe Anesthetics. http://www.mhaus.org/healthcare-professionals/be-prepared/safeand-unsafe-anesthetics.

36. Hemmings HC Jr. Sodium channels and the synaptic mechanisms of inhaled anaesthetics. Br J Anaesth. 2009; 103:61-69. [PubMed: 19508978]

37. Campagna JA, Miller KW, et al. Mechanisms of actions of inhaled anesthetics. N Engl J Med. 2003; 348:2110-2124. [PubMed: 12761368]

38. Perouansky, M.; Pearce, R., et al. Chapter 25: Inhaled Anesthetics. In: Miller, R., editor. Miller's Anesthesia. 8th edition. Vol. 8. Philadelphia, PA: Elsevier Saunders; 2015.

39. Diaz-Sylvester PL, Porta M, et al. Halothane modulation of skeletal muscle ryanodine receptors: dependence on Ca2+, Mg2+, and ATP. Am J Physiol Cell Physiol. 2008; 294:C1103-C1112. [PubMed: 18305228]

40. Kosk-Kosicka D, Fomitcheva I, et al. Heterogeneous halothane binding in the SR Ca2+-ATPase. FEBS Lett. 1997; 402:189-192. [PubMed: 9037193]

41. Nelson TE, Sweo T. Ca2+ uptake and Ca2+ release by skeletal muscle sarcoplasmic reticulum: differing sensitivity to inhalational anesthetics. Anesthesiology. 1988; 69:571-577. [PubMed: 3177917]

42. Appiah-Ankam J, Hunter JM. Pharmacology of neuromuscular blocking drugs. Continuing Education in Anaesthesia, Critical Care \& Pain. 2004; 4:2-7. 
43. Alvarellos ML, McDonagh EM, et al. PharmGKB summary: succinylcholine pathway, pharmacokinetics/pharmacodynamics. Pharmacogenet Genomics. 2015; 25:622-630. [PubMed: 26398623]

44. Iaizzo PA, Johnson BA, et al. 4-chloro-m-cresol triggers malignant hyperthermia in susceptible swine at doses greatly exceeding those found in drug preparations. Anesthesiology. 1999; 90:1723-1732. [PubMed: 10360872]

45. Baur CP, Bellon L, et al. A multicenter study of 4-chloro-m-cresol for diagnosing malignant hyperthermia susceptibility. Anesth Analg. 2000; 90:200-205. [PubMed: 10625004]

46. Dexter F, Epstein RH, et al. Estimate of the relative risk of succinylcholine for triggering malignant hyperthermia. Anesth Analg. 2013; 116:118-122. [PubMed: 23223104]

47. Rosenberg, H.; Sambuughin, N., et al. Malignant Hyperthermia Susceptibility. In: Pagon, RA.; Adam, MP., et al., editors. GeneReviews(R). Seattle (WA): 1993.

48. Guerrero-Hernandez A, Avila G, et al. Ryanodine receptors as leak channels. Eur J Pharmacol. 2014; 739:26-38. [PubMed: 24291096]

49. Robinson RL, Brooks C, et al. RYR1 mutations causing central core disease are associated with more severe malignant hyperthermia in vitro contracture test phenotypes. Hum Mutat. 2002; 20:88-97. [PubMed: 12124989]

50. Carpenter D, Robinson RL, et al. Genetic variation in RYR1 and malignant hyperthermia phenotypes. Br J Anaesth. 2009; 103:538-548. [PubMed: 19648156]

51. Lopez JR, Linares N, et al. Enhanced response to caffeine and 4-chloro-m-cresol in malignant hyperthermia-susceptible muscle is related in part to chronically elevated resting [Ca2+]i. Am J Physiol Cell Physiol. 2005; 288:C606-C612. [PubMed: 15537710]

52. Eltit JM, Ding X, et al. Nonspecific sarcolemmal cation channels are critical for the pathogenesis of malignant hyperthermia. FASEB J. 2013; 27:991-1000. [PubMed: 23159934]

53. Tong J, McCarthy TV, et al. Measurement of resting cytosolic $\mathrm{Ca} 2+$ concentrations and $\mathrm{Ca} 2+$ store size in HEK-293 cells transfected with malignant hyperthermia or central core disease mutant Ca2+ release channels. J Biol Chem. 1999; 274:693-702. [PubMed: 9873004]

54. Yang T, Esteve E, et al. Elevated resting $[\mathrm{Ca}(2+)](\mathrm{i})$ in myotubes expressing malignant hyperthermia RyR1 cDNAs is partially restored by modulation of passive calcium leak from the SR. Am J Physiol Cell Physiol. 2007; 292:C1591-C1598. [PubMed: 17182726]

55. Stowell KM. Malignant hyperthermia: a pharmacogenetic disorder. Pharmacogenomics. 2008; 9:1657-1672. [PubMed: 19018722]

56. Canato M, Capitanio P, et al. The disorders of the calcium release unit of skeletal muscles: what have we learned from mouse models? J Muscle Res Cell Motil. 2015; 36:61-69. [PubMed: 25424378]

57. Mareedu RK, Modhia FM, et al. Use of an electronic medical record to characterize cases of intermediate statin-induced muscle toxicity. Prev Cardiol. 2009; 12:88-94. [PubMed: 19476582]

58. Wilke RA, Lin DW, et al. Identifying genetic risk factors for serious adverse drug reactions: current progress and challenges. Nat Rev Drug Discov. 2007; 6:904-916. [PubMed: 17971785]

59. Alfirevic A, Neely D, et al. Phenotype standardization for statin-induced myotoxicity. Clin Pharmacol Ther. 2014; 96:470-476. [PubMed: 24897241]

60. Larson EA, Wilke RA. Integration of Genomics in Primary Care. Am J Med. 2015

61. Wilke RA, Mareedu RK, et al. The Pathway Less Traveled: Moving from Candidate Genes to Candidate Pathways in the Analysis of Genome-Wide Data from Large Scale Pharmacogenetic Association Studies. Curr Pharmacogenomics Person Med. 2008; 6:150-159. [PubMed: 19421424]

62. Feng Q, Wilke RA, et al. Individualized risk for statin-induced myopathy: current knowledge, emerging challenges and potential solutions. Pharmacogenomics. 2012; 13:579-594. [PubMed: 22462750]

63. Marciante KD, Durda JP, et al. Cerivastatin, genetic variants, and the risk of rhabdomyolysis. Pharmacogenet Genomics. 2011; 21:280-288. [PubMed: 21386754]

64. Dlamini N, Voermans NC, et al. Mutations in RYR1 are a common cause of exertional myalgia and rhabdomyolysis. Neuromuscul Disord. 2013; 23:540-548. [PubMed: 23628358] 
65. Timmins MA, Rosenberg H, et al. Malignant Hyperthermia Testing in Probands without Adverse Anesthetic Reaction. Anesthesiology. 2015; 123:548-556. [PubMed: 26068069]

66. Sambuughin N, Capacchione J, et al. The ryanodine receptor type 1 gene variants in African American men with exertional rhabdomyolysis and malignant hyperthermia susceptibility. Clin Genet. 2009; 76:564-568. [PubMed: 19807743]

67. Abecasis GR, et al. Genomes Project, C. An integrated map of genetic variation from 1,092 human genomes. Nature. 2012; 491:56-65. [PubMed: 23128226]

68. Sewry CA, Muller C, et al. The spectrum of pathology in central core disease. Neuromuscul Disord. 2002; 12:930-938. [PubMed: 12467748]

69. Avila G, Dirksen RT. Functional effects of central core disease mutations in the cytoplasmic region of the skeletal muscle ryanodine receptor. J Gen Physiol. 2001; 118:277-290. [PubMed: $11524458]$

70. Robinson R, Carpenter D, et al. Mutations in RYR1 in malignant hyperthermia and central core disease. Hum Mutat. 2006; 27:977-989. [PubMed: 16917943]

71. Jungbluth H. Multi-minicore Disease. Orphanet J Rare Dis. 2007; 2:31. [PubMed: 17631035]

72. Treves S, Jungbluth H, et al. Congenital muscle disorders with cores: the ryanodine receptor calcium channel paradigm. Curr Opin Pharmacol. 2008; 8:319-326. [PubMed: 18313359]

73. Hopkins PM, Ruffert H, et al. European Malignant Hyperthermia Group guidelines for investigation of malignant hyperthermia susceptibility. Br J Anaesth. 2015

74. MHAUS GUIDELINES. Testing for Malignant Hyperthermia Susceptibility: How do I counsel my patients?. http://www.mhaus.org/public/testing/counseling-patients-slideshow.pdf.

75. MHAUS Testing Centers. http://www.mhaus.org/testing/centers.

76. EMHG Genetics. Mutations in RYR1. https://emhg.org/genetics/mutations-in-ryr1.

77. Weiss RG, O'Connell KM, et al. Functional analysis of the R1086H malignant hyperthermia mutation in the DHPR reveals an unexpected influence of the III-IV loop on skeletal muscle EC coupling. Am J Physiol Cell Physiol. 2004; 287:C1094-C1102. [PubMed: 15201141]

78. Stewart SL, Hogan K, et al. Identification of the Arg1086His mutation in the alpha subunit of the voltage-dependent calcium channel (CACNA1S) in a North American family with malignant hyperthermia. Clin Genet. 2001; 59:178-184. [PubMed: 11260227]

79. Carpenter D, Ringrose C, et al. The role of CACNA1S in predisposition to malignant hyperthermia. BMC Med Genet. 2009; 10:104. [PubMed: 19825159]

80. Stowell KM. DNA testing for malignant hyperthermia: the reality and the dream. Anesth Analg. 2014; 118:397-406. [PubMed: 24445638]

81. Gonsalves SG, Ng D, et al. Using exome data to identify malignant hyperthermia susceptibility mutations. Anesthesiology. 2013; 119:1043-1053. [PubMed: 24195946]

82. Bethesda (MD): National Center for Biotechnology Information, National Library of Medicine; Database of Single Nucleotide Polymorphisms (dbSNP). (dbSNP Build ID: \{build 145\}) http:// www.ncbi.nlm.nih.gov/SNP/ [Accessed [August 6, 2015]]

83. Urwyler A, Deufel T, et al. Guidelines for molecular genetic detection of susceptibility to malignant hyperthermia. Br J Anaesth. 2001; 86:283-287. [PubMed: 11573677]

84. Robinson RL, Hopkins PM. A breakthrough in the genetic diagnosis of malignant hyperthermia. $\mathrm{Br}$ J Anaesth. 2001; 86:166-168. [PubMed: 11573654]

85. Schiemann AH, Paul N, et al. Functional characterization of 2 known ryanodine receptor mutations causing malignant hyperthermia. Anesth Analg. 2014; 118:375-380. [PubMed: 24361844]

86. Litman RS, Rosenberg H. Malignant hyperthermia: update on susceptibility testing. JAMA. 2005; 293:2918-2924. [PubMed: 15956637]

87. Allen PD, Lopez JR. "Noninvasive" testing for malignant hyperthermia susceptibility. Anesthesiology. 2002; 97:1045-1046. [PubMed: 12411783] 